\title{
THE ANTIGENIC COMPOSITION OF CRYPTOCOCCUS NEOFORMANS
}

\author{
V. A Survey of Cross-Reactions among Strains of Cryptococcus and other \\ Antigens $^{1}$
}

\author{
E. EDWARD EVANS, LLOYD J. SORENSEN, AND KENNETH W. WALLS \\ Department of Bacteriology, University of Michigan, Ann Arbor, Michigan
}

Received for publication February 28, 1953

Serologic methods are becoming increasingly important in the diagnosis of mycotic infections. Necessary prerequisites for the evaluation of such tests should include information on the antigenic relationships of strains within a species as well as relationships with other species, both closely and distantly related.

Several investigations of interspecies cross reactions among fungi have appeared during the past few years (Campbell and Saslaw, 1948; Pates, 1948; Salvin, 1949, 1950; Saslaw and Campbell, 1948; Tenenberg and Howell, 1948). The existence of more than one antigenic type within the species Cryptococcus neoformans also has been reported (Evans, 1950). The possibility of using a serologic test in the diagnosis of cryptococcosis (Neill et al., 1951) suggests a need for further knowledge of the antigenic relationships among cryptococci and other microorganisms, particularly those likely to cause cerebrospinal infection.

The purpose of this paper is to present information on cross reactions occurring among strains of $C$. neoformans and antigens of other microorganisms and higher forms.

\section{MATERIALS AND METHODS}

Immunizing antigen. Four strains of Cryptococcus neoformans were employed for preparing immunizing antigens: RE and 4189 (Type A); 1523 (Type B); and LE (Type C). All strains were plated out repeatedly to secure small capsule variants (Neill et al., 1950); however, complete success was obtained with only the LE and RE strains. The remaining two (1523 and 4189) retained a moderate sized capsule. Each strain was grown in one liter of neopeptone dialysate-

1 This investigation was supported by research grants from the Faculty Research Fund of the Horace H. Rackham School of Graduate Studies and the National Institutes of Health, Public Health Service (Project E-436). glucose medium with constant mechanical agitation at room temperature (Evans and Theriault, 1953). After 24 hours of incubation, the cells were removed by centrifugation and resuspended in $100 \mathrm{ml}$ of saline containing 1 per cent formalin. These suspensions were placed at $37 \mathrm{C}$ for 12 hours and then adjusted to a concentration $4 \times$ $10^{8}$ cells per $\mathrm{ml}$ by hemocytometer count. The stock vaccines were stored in the cold, and before injection a measured quantity of cellular suspension was centrifuged and resuspended in fresh saline solution.

Antiserum. Rabbits weighing approximately 5 pounds were bled to obtain pre-immunization serum and then injected intravenously on the first 3 days of each week with $1 \mathrm{ml}$ of antigen $\left(4 \times 10^{8}\right.$ cells). Antibodies were demonstrable in most rabbits after 21 to 30 injections ( 7 to 10 weeks); however, injections were continued for longer periods of time to secure higher titered antisera. Antisera from each bleeding were given a separate number. A partial list of sera, prepared in this study, is given in table 2. Titers for the capsular "quellung", reaction are indicated. In most cases, tube agglutination titers are 4 to 8 times as high as the quellung titers.

A "polyvalent" antiserum capable of reacting equally well with types $\mathrm{A}, \mathrm{B}$, and $\mathrm{C}$ has been prepared by injecting rabbits with a vaccine containing equal numbers of strains RE, 1523, and LE with a total count of $4 \times 10^{8}$ cells per ml. The immunization schedule and dose were

2 The term "quellung" has been used for convenience and also because of the resemblance of the reaction to capsular reactions of the pneumococcus and other bacteria. Since the term "quellung" implies a swelling of the capsule, it should be noted that there does not appear to be any marked increase in size of the cryptococcus capsule when mixed with antiserum, but only a clarification of its outline (Neill et al., 1950; Evans, 1950). 
the same as those used for the preparation of typing antisera. Since antibodies for each type did not always appear at the same rate, it was found necessary to substitute occasional injections of "monovalent" antigen for the type yielding a low antibody response.

In cross reaction studies, commercially prepared typing sera were employed.

Antigens. Cryptococcus soluble antigens were prepared by growing cultures at room temperature with constant agitation in neopeptone dialysate glucose medium (Evans and Theriault, 1953). Cells for quellung reactions were obtained from neopeptone dialysate agar cultures and from peritoneal cavities of infected mice. Peritoneal
S2, blood group A substance, gum acacia USP, and gum tragacanth USP. The gum tragacanth was purified partially by precipitating the water soluble portion with 2 volumes of acetone in the presence of 10 per cent sodium acetate. Two such precipitations yielded a product which formed a clear solution in water.

Serologic tests. Agglutination and quellung reactions were conducted as in a previous study (Evans, 1950). All cells were washed twice with saline immediately prior to performing quellung tests. Precipitin tests were conducted by the qualitative ring technique. Antigen $(0.1 \mathrm{ml})$ was layered over $0.1 \mathrm{ml}$ of undiluted or $1: 5$ dilution of antiserum in a 6 by $50 \mathrm{~mm}$ tube. Tests were

TABLE 1

Agglutinin titers in unabsorbed anticryptococcal serum

\begin{tabular}{|c|c|c|c|c|c|c|c|c|}
\hline \multirow{3}{*}{ SPECIES } & \multirow{3}{*}{ STRAIN } & \multicolumn{7}{|c|}{ ANTISERUM } \\
\hline & & \multicolumn{3}{|c|}{ Type A } & \multicolumn{2}{|c|}{ Type B } & \multicolumn{2}{|c|}{ Type C } \\
\hline & & 12 & 44 & 60 & 38 & 39 & 42 & 43 \\
\hline \multirow[t]{3}{*}{ Cryptococcus neoformans } & $\mathrm{RE}(\mathrm{A})$ & 80 & 80 & 320 & 80 & 160 & 40 & $<20$ \\
\hline & $\mathrm{L} 2(\mathrm{~B})$ & $<20$ & $<20$ & 80 & 160 & 160 & 80 & $<20$ \\
\hline & LE $(\mathrm{C})$ & $<20$ & 40 & 40 & 40 & 40 & 160 & 320 \\
\hline Histoplasma capsulatum & DKU & $<2$ & $<2$ & $<2$ & $<2$ & $<2$ & $<2$ & $<2$ \\
\hline Blastomyces dermatitidis & BD7 & $<2$ & $<2$ & $<2$ & $<2$ & $<2$ & $<2$ & $<2$ \\
\hline Saccharomyces cerevisiae & - & $160^{*}$ & $2,560^{*}$ & $1,280^{*}$ & $320^{*}$ & $640^{*}$ & $320^{*}$ & $2,560^{*}$ \\
\hline Candida albicans & $\mathrm{UH}$ & $<2$ & $<2$ & $<2$ & $<2$ & $80^{*}$ & $80^{*}$ & $80^{*}$ \\
\hline
\end{tabular}

Expressed as reciprocal of dilution.

* Fine granular agglutination.

washings from the mice were employed also in precipitin tests.

For agglutination tests, $C$. neoformans, Candida albicans, and Saccaromyces cerevisiae were grown in neopeptone dialysate glucose medium at room temperature with constant agitation. Yeast phase cells of Histoplasma capsulatum and Blastomyces dermatitidis were grown under similar conditions at $37 \mathrm{C}$.

These antigens were adjusted to approximately 70 per cent transmittance in a Klett-Summerson photoelectric colorimeter with a green filter (500 to $570 \mu$ ).

Commercially prepared histoplasmin, blastomycin, and trichophytin were used in precipitin tests. Coccidioidin used was prepared by the method of Smith et al. (1950).

Also included in cross reaction studies were pneumococcus capsular polysaccharides S1 and read at the end of 2 hours' incubation at room temperature and again after 12 hours of refrigeration.

\section{RESULTS}

The specificity of antisera produced in this study is of about the same order as the earlier products (Evans, 1950). There was some cross reaction between types $\mathrm{A}, \mathrm{B}$, and $\mathrm{C}$, but the antigenic differences are marked, even with unabsorbed antiserum. Type B antisera reacted strongly with type A antigen and in one case, serum 9-1523-40 (table 2) reacted at 1:2 with type A cells before demonstrable antibody to type B had developed. In general, the agglutination tests (table 1) display somewhat more cross reaction than quellung reactions (tables 2 and 3 ). The comparison of cells from neopeptone dialysate culture and mouse peritoneum in table 3 has 
revealed a point not previously noted. The cells from infected animals have a somewhat different specificity than cells from culture, particularly in the case of strain LE (type C). This strain, when grown in culture, produced quellung reactions with type $\mathrm{C}$ antisera 42 and 43 at dilutions of $1: 10$ and $1: 80$, respectively, yet these antisera did not react with type $\mathrm{C}$ cells from infected mice. Evidence that this may be a quantitative difference is seen in the fact that type $\mathrm{C}$ serum no. 48 will react at $1: 20$ with type $C$ cells from mice. This serum, however, displays a stronger cross reaction with types $\mathrm{A}$ and $\mathrm{B}$ than do sera 42 and 43.

A possible explanation for the failure of type $\mathrm{C}$ cells to react with antiserum would be the presence of sufficient dissolved capsular polysaccharide to compete with the capsule for antibody. However, three washings of the cells prior to performing quellung tests failed to enhance the reactions in antisera 42 and 43 . Another observation provided direct proof of an antigenic difference between cells from culture and cells from infected mice. When mice infected with type $\mathrm{C}$ cells were sacrificed within a few days after intraperitoneal inoculation, both the "small capsule cells" from the inoculum and the "large capsule cells" typical of infected animals could be found within the peritoneal fluid. The cells with small capsules produced a quellung reaction with antisera 42 and 43 , whereas the large capsule organisms did not. The cells with large capsules were not observed to be phagocytized, but many of the small capsule forms were inside phagocytes and were observed to yield a positive quellung reaction in this location.

Dissolved polysaccharide present in cultural supernate or in cell-free washings from the peritoneal cavities of infected mice (table 4) exhibited reactivity with antiserum that was roughly parallel to results with the quellung reaction. The polyvalent serum reacted strongly with all antigens tested both in the quellung and precipitin tests. Among 36 strains of $C$. neoformans from human infections tested to date, none has failed to react in polyvalent antiserum.

In interspecies tests, cross agglutination was secured with $C$. albicans and S. cerevisiae in anticryptococcus serum. The titers with $S$. cerevisiae antigen exceeded titers for the homologous strain (table 1). C. albicans reacted with only one type $\mathrm{B}$ antiserum and both type $\mathrm{C}$ serums. Pure yeast phase cells of $H$. capsulatum and $B$. dermatitidis
TABLE 2

Quellung reactions in homologous and heterologous antiserum

\begin{tabular}{|c|c|c|c|}
\hline \multirow{2}{*}{ ANTISERUM } & \multicolumn{3}{|c|}{$\begin{array}{c}\text { STRAIN OF CRYPTOCOCCUS } \\
\text { NEOFORMANS }\end{array}$} \\
\hline & $\operatorname{RE}(\mathrm{A})$ & L2 (B) & LE (C) \\
\hline \multicolumn{4}{|l|}{ Cryptococcus A } \\
\hline 1-RE-12* (24) & 20 & 2 & $<2$ \\
\hline 2-RE-8 (24) & 10 & 2 & $<2$ \\
\hline 21-RE-44 (51) & 10 & $<2$ & 2 \\
\hline 21-RE-60 (72) & 80 & 2 & 2 \\
\hline 22-RE-18 (27) & 2 & $<2$ & $<2$ \\
\hline 23-RE-45 (54) & 2 & $<2$ & $<2$ \\
\hline $13-4189-46(60)$ & 2 & $<2$ & $<2$ \\
\hline $19-4189-19(33)$ & 2 & $<2$ & $<2$ \\
\hline \multicolumn{4}{|l|}{ Cryptococcus B } \\
\hline $7-1523-38(51)$ & 40 & 40 & $<2$ \\
\hline $8-1523-39(48)$ & 20 & 20 & $<2$ \\
\hline $8-1523-47(60)$ & 20 & 40 & 10 \\
\hline $9-1523-40(51)$ & 2 & $<2$ & $<2$ \\
\hline \multicolumn{4}{|l|}{ Cryptococcus C } \\
\hline 6-LE-56 (68) & $<2$ & $<2$ & 2 \\
\hline 17-LE-43 (41) & $<2$ & $<2$ & 80 \\
\hline 18-LE-42 (41) & $<2$ & $<2$ & 10 \\
\hline 18-LE-48 (50) & 10 & 10 & 40 \\
\hline \multicolumn{4}{|l|}{$\begin{array}{l}\text { Salmonella } \\
\quad(\text { Groups A-E and Vi) }\end{array}$} \\
\hline Klebsiella pneumoniae A & $<2$ & $<2$ & $<2$ \\
\hline Klebsiella pneumoniae B & $<2$ & $<2$ & $<2$ \\
\hline Klebsiella pneumoniae C & $<2$ & $<2$ & $<2$ \\
\hline $\begin{array}{l}\text { Meningococcus } \\
\text { (Polyvalent) }\end{array}$ & $<2$ & $<2$ & $<2$ \\
\hline Pneumococcus 1 & $<2$ & $<2$ & $<2$ \\
\hline Pneumococcus 2 & 2 & $<2$ & $<2$ \\
\hline Streptococcus A & $<2$ & $<2$ & $<2$ \\
\hline Streptococcus B & $<2$ & $<2$ & $<2$ \\
\hline Streptococcus C & $<2$ & $<2$ & $<2$ \\
\hline Hemophilus influenzae a & $<2$ & $<2$ & $<2$ \\
\hline Hemophilus influenzae $\mathrm{b}$ & $<2$ & $<2$ & $<2$ \\
\hline
\end{tabular}

Reactivity expressed as reciprocal of highest dilution yielding a clearly visible capsular reaction.

* Nomenclature used for antisera: numerals and letters in order of their appearance designate rabbit number, strain of Cryptococcus neoformans, serum number. The figure in parentheses indicates the number of antigen injections prior to bleeding. 
TABLE 3

Quellung reactions* of cells from culture and from infected mice

\begin{tabular}{|c|c|c|c|c|c|c|c|c|c|c|c|}
\hline \multirow{3}{*}{ SOURCE OF CELLS } & \multirow{3}{*}{ TYPE } & \multirow{3}{*}{ STRAIN } & \multicolumn{9}{|c|}{ ANTISERUM } \\
\hline & & & \multicolumn{3}{|c|}{ Type A } & \multicolumn{2}{|c|}{ Type B } & \multicolumn{3}{|c|}{ Type C } & \multirow{2}{*}{$\frac{\text { Polyvalent }}{70}$} \\
\hline & & & 12 & 44 & 60 & 38 & 39 & 42 & 43 & 48 & \\
\hline \multirow[t]{5}{*}{ Neopeptone dialysate medium } & A & $\mathrm{RE}$ & 20 & 10 & 80 & 40 & 20 & $<2$ & $<2$ & 10 & 160 \\
\hline & & $\mathrm{DU}$ & 20 & 10 & 80 & 40 & 20 & $<2$ & $<2$ & 10 & 160 \\
\hline & $\mathrm{B}$ & 1523 & 2 & $<2$ & 2 & 40 & 20 & $<2$ & $<2$ & 10 & 160 \\
\hline & & L2 & 2 & $<2$ & 2 & 40 & 20 & $<2$ & $<2$ & 10 & 160 \\
\hline & $\mathrm{C}$ & LE & $<2$ & 2 & 2 & $<2$ & $<2$ & 10 & 80 & 40 & 80 \\
\hline \multirow[t]{5}{*}{ Mouse peritoneum } & A & $\mathrm{RE}$ & 20 & 20 & 40 & 40 & 10 & $<2$ & $<2$ & 2 & 80 \\
\hline & & $\mathrm{DU}$ & 20 & 20 & 40 & 40 & 10 & $<2$ & $<2$ & 2 & 80 \\
\hline & B & 1523 & 2 & $<2$ & 2 & 40 & 10 & $<2$ & $<2$ & 10 & 80 \\
\hline & & $\mathrm{L} 2$ & 2 & $<2$ & 2 & 40 & 10 & $<2$ & $<2$ & 10 & 80 \\
\hline & $\mathrm{C}$ & $\mathrm{LE}$ & 10 & $<2$ & 10 & 10 & 2 & $<2$ & $<2$ & 20 & 40 \\
\hline
\end{tabular}

* Expressed as reciprocal of dilution of unabsorbed antiserum yielding clearly visible capsular reaction.

TABLE 4

Precipitation of cryptococcus soluble antigen in anticryptococcal serum

\begin{tabular}{|c|c|c|c|c|c|c|c|c|c|c|}
\hline \multirow{3}{*}{ SOURCE OF ANTIGEN } & \multirow{3}{*}{ TYPE } & \multirow{3}{*}{ STRAIN } & \multicolumn{8}{|c|}{ ANTISERUM* } \\
\hline & & & \multicolumn{3}{|c|}{ Type A } & \multicolumn{2}{|c|}{ Type B } & \multicolumn{2}{|c|}{ Type C } & \multirow{2}{*}{$\frac{\text { Polyvalent }}{68}$} \\
\hline & & & 12 & 44 & 60 & 38 & 39 & 42 & 43 & \\
\hline \multirow{8}{*}{$\begin{array}{l}\text { Neopeptone dialysate cul- } \\
\text { tural supernate }\end{array}$} & A & $\mathrm{RE}$ & + & + & + & + & + & - & - & + \\
\hline & & $\mathrm{DU}$ & + & + & + & + & + & - & - & + \\
\hline & & 4189 & + & + & + & + & + & - & - & + \\
\hline & & 2526 & + & + & + & + & + & - & - & + \\
\hline & B & 1523 & - & - & - & + & + & - & - & + \\
\hline & & L2 & - & - & - & + & + & - & - & + \\
\hline & & 2517 & - & - & - & + & + & - & - & + \\
\hline & $\mathrm{C}$ & LE & - & + & - & - & - & + & + & + \\
\hline \multirow[t]{7}{*}{ Mouse peritoneal fluid } & A & $\mathrm{RE}$ & + & + & + & + & + & - & - & + \\
\hline & & $\mathrm{DU}$ & + & + & + & + & + & - & - & + \\
\hline & & 4189 & + & + & + & + & + & - & - & + \\
\hline & B & 1523 & - & - & - & + & + & - & - & + \\
\hline & & $\mathrm{L} 2$ & - & - & - & + & + & - & - & + \\
\hline & & 2517 & - & - & - & + & + & - & - & + \\
\hline & $\mathrm{C}$ & LE & - & - & - & - & - & - & - & + \\
\hline
\end{tabular}

* Antiserum diluted 1:5. 
failed to agglutinate in any anticryptococcal serum.

In precipitin tests, no reaction was secured with histoplasmin, blastomycin, or coccidioidin. However, a strong reaction was produced in all tragacanth precipitated with cryptococcus antisera nos. 44, 60, and 68. A similar cross reaction has been secured also with antise:um A-2 used in earlier work (Evans and Kessel, 1951). Thus, there appears to be an antigenic relation between

TABLE 5

Precipitation of heterologous antigens in anticryptococcal serum

\begin{tabular}{|c|c|c|c|c|c|c|c|c|c|}
\hline \multirow{3}{*}{ ANTIGEN } & \multirow{3}{*}{\begin{tabular}{|l} 
ANTIGEN \\
CONCENTRATION
\end{tabular}} & \multicolumn{8}{|c|}{ ANTISERUM ${ }^{*}$} \\
\hline & & \multicolumn{3}{|c|}{ Type A } & \multicolumn{2}{|c|}{ Type B } & \multicolumn{2}{|c|}{ Type C } & \multirow{2}{*}{$\frac{\text { Polyvalent }}{68}$} \\
\hline & & 12 & 44 & 60 & 38 & 39 & 42 & 43 & \\
\hline & $m g / m l$ & & & & & & & & \\
\hline \multirow{2}{*}{ Histoplasmin } & & - & - & - & - & - & - & - & - \\
\hline & & _ & - & - & - & _ & _- & - & - \\
\hline \multirow{3}{*}{ Blastomycin } & * & - & _ & - & - & - & - & - & - \\
\hline & $\dagger$ & - & - & - & - & - & - & - & - \\
\hline & $\ddagger$ & - & - & - & - & - & - & - & - \\
\hline \multirow[t]{2}{*}{ Coccidioidin } & * & - & - & - & - & - & - & - & - \\
\hline & $\ddagger$ & - & - & - & - & - & - & - & - \\
\hline Trichophytin & $\S$ & + & + & + & + & + & + & + & + \\
\hline \multicolumn{10}{|l|}{ Pneumococcus } \\
\hline \multirow[t]{2}{*}{ S1 } & 2.0 & - & - & - & - & - & - & - & - \\
\hline & 0.2 & - & - & - & - & - & - & - & - \\
\hline \multirow[t]{2}{*}{$\mathrm{S} 2$} & 2.0 & - & - & + & - & - & - & - & + \\
\hline & 0.2 & - & - & + & - & - & - & - & + \\
\hline \multirow[t]{2}{*}{ Blood group A substance } & 2.0 & - & - & - & - & - & - & - & - \\
\hline & 0.2 & - & - & - & - & - & - & - & - \\
\hline \multirow[t]{2}{*}{ Gum tragacanth } & 2.0 & - & + & + & - & - & - & - & + \\
\hline & 0.2 & - & \pm & \pm & - & - & - & - & \\
\hline \multirow[t]{2}{*}{ Gum acacia } & 2.0 & - & - & - & - & - & - & - & - \\
\hline & 0.2 & - & - & - & - & - & - & - & - \\
\hline
\end{tabular}

* Undiluted.

$\dagger 1: 10$ dilution.

$\$ 1: 100$ dilution.

$\S 1: 30$ dilution.

\pm Weak reaction (ring test).

+ Strong reaction.

antisera by trichophytin. This antigen did not react with normal rabbit serum.

A cross reaction was secured with pneumococcus S2 in antisera nos. 60 and 68. Likewise, pneumococcus type 2 antiserum produced quellung of cryptococcus type A cells (table 2). Gum cryptococcus type A polysaccharide and gum tragacanth.

When several antibacterial typing serums were employed in quellung tests with cryptococcus cells, the only positive reaction obtained was the quellung of cryptococcus type A cells in 
type 2 pneumococcus antiserum. The other serums tested are listed in table 2 .

The cross reaction in type $A$ and $B$ antisera of three strains isolated from soil (Emmons, 1951) is interesting from an epidemiological standpoint. Although the quellung titers of these three cultures are somewhat lower than the homologous titers, there is an obvious antigenic relationship with the type $A$ and $B$ strains which were isolated from fatal infections in man.

TABLE 6

Quellung reactions of Cryptococcus neoformans strains isolated from soil

\begin{tabular}{l|r|r|r|r}
\hline \multirow{2}{*}{ STrain } & \multicolumn{4}{|c}{ ANTISERUM } \\
\cline { 2 - 5 } & A (60) & B (39) & C (43) & $\begin{array}{c}\text { Poly- } \\
\text { valent } \\
(70)\end{array}$ \\
\hline $\begin{array}{l}\text { Homologous } \\
\text { quellung titer }\end{array}$ & 80 & 20 & 80 & $80-160$ \\
3719 & 20 & 10 & $<10$ & 80 \\
3720 & 20 & 20 & $<10$ & 40 \\
3721 & 10 & 20 & $<10$ & 40 \\
\hline
\end{tabular}

\section{DISCUSSION}

The present survey has demonstrated serologic relationships among $C$. neoformans and several other antigens. Cross reactions were secured with C. albicans, S. cerevisiae, trichophytin, pneumococcus type 2 , and gum tragacanth. It is significant that no cross reactions were obtained with some other fungi which cause deep-seated infection (H. capsulatum, B. dermatitidis, and Coccidioides immitis). These observations provide a foundation for further studies on a possible diagnostic test for cryptococcosis in which spinal fluid from the patient is tested for the presence of soluble antigen using precipitating antibody from immunized rabbits (Neill et al., 1951). Further tests for specificity are indicated, using spinal fluid from "normal" humans as well as from patients suffering from deep-seated mycoses and neurological disorders which may be confused with cryptococcosis. The cross reaction of cryptococcus type A with pneumococcus S2 and gum tragacanth is of fundamental interest. Possibly further study will clarify the chemical basis for these cross reactions.

The use of polyvalent anticryptococcal serum would appear to be preferable to typing serum for routine diagnostic work although typing serum might find application in epidemiologic surveys. The antisera prepared by Neill and Kapros (1950) appear to exhibit more cross reaction than the typing sera prepared in this study. However, the data presented by these authors do not indicate the extent of cross reaction. It is entirely possible that their antisera were similar to our serum no. 8-1523-47 (table 2) which cross reacts with all three types. The different immunization schedule employed by Neill et al. (1950) also may be a factor affecting specificity of antiserums although a critical experiment involving large numbers of animals would be necessary to prove this point. The degree of cross reactivity of an antiserum may depend also on individual differences in the animals used as well as on the length of the immunization period. The latter factor would appear to be important in the case of antiserum 8-1523-47 since an earlier bleeding from the same animal (8-1523-39) failed to cross react with type C.

Although $C$. neoformans is not a dimorphic organism, there appears to be an antigenic difference between organisms from the animal body and from culture, particularly with the type $\mathrm{C}$ strain. It seems possible that similar differences may occur with other pathogenic fungi. Lindberg (1950) has presented evidence for an antigenic difference between mycelial and yeast phase cultures of $H$. capsulatum and it would seem that an extension of these observations might yield valuable information.

\section{ACKNOWLEDGMENT}

The authors wish to express appreciation to Dr. E. R. Harrell for supplying trichophytin, Dr. Darwin Alonso for blood group A substance, Dr. C. E. Smith for coccidioidin, and the Eli Lilly Company for histoplasmin and blastomycin used in this investigation.

\section{SUMMARY}

A survey of serologic cross reactions occurring among strains of Cryptococcus neoformans, other fungi, bacteria, and polysaccharides from higher forms has been presented. Antigens from Histoplasma capsulatum, Blastomyces dermatitidis, and Coccidioides immitis did not react in anticryptococcal sera. Cross reactions were secured with Candida albicans, Saccharomyces cerevisiae, and trichophytin. Cross reactions were secured also with pneumococcus type 2 and gum tragacanth 
against some anticryptococcal sera. Strains of $C$. neoformans isolated from soil reacted in type $\mathrm{A}$, type $\mathrm{B}$, and polyvalent anticryptococcal sera. A method is described for preparing polyvalent antiserum which is capable of reacting with the three known types of $C$. neoformans. Cells of C. neoformans type $\mathrm{C}$ from infected mice appear to be antigenically different from cells grown in culture.

\section{REFERENCES}

Campbeil, C. C., and Saslaw, S. 1948 The use of yeast phase antigens in a complement fixation test for histoplasmosis. II. Results with ground antigens. J. Lab. Clin. Med., 33, 1207-1211.

Emmons, C. W. 1951 Isolation of Cryptococcus neoformans from soil. J. Bact., 62, 685-690.

Evans, E. E. 1950 The antigenic composition of Cryptococcus neoformans. I. A serologic classification by means of the capsular and agglutination reactions. J. Immunol., 64, 423-430.

Evans, E. E., And Kessel, J. F. 1951 The antigenic composition of Cryptococcus neoformans. II. Serologic studies with the capsular polysaccharide. J. Immunol., 67, 109-114.

Evans, E. E., And Theriault, R. J. 1953 The antigenic composition of Cryptococcus neoformans. IV. The use of paper chromatography for following purification of the capsular polysaccharide. J. Bact., 65, 571-577.

LindBeRG, R. B. 1950 The antigenic structure of Histoplasma capsulatum, particularly the yeast phase. Ph.D. Dissertation, University of Michigan.
Nejll, J. M., and Kay'ros, C. E. 1950 Serological tests on soluble antigens from mice infected with Cryptococcus neoformans and Sporotrichum schenckii. Proc. Soc. Exptl. Biol. Med., 73, 557-559.

Neill, J. M., Abrahams, I., and Kapros, C. E. 1950 A comparison of the immunogenicity of weakly encapsulated and of strongly encapsulated strains of Cryptococcus neoformans (Torula histolytica). J. Bact., 59, 263-275.

Neill, J. M., Sugg, J. Y., and McCauley, D. W. 1951 Serologically reactive material in spinal fluid, blood and urine from a human case of cryptococcosis (torulosis). Proc. Soc. Exptl. Biol. Med., 77, 775-778.

Pates, A. L. 1948 Precipitin reactions in ex. perimental histoplasmosis and blastomycosis. Science, 108, 383-385.

SAlvin, S. B. 1949 The serologic relationships of fungus antigens. J. Lab. Clin. Med., 34, 1096-1104.

SAlvin, S. B. 1950 Quantitative studies on the serologic relationships of fungi. J. Immunol., $55,617-626$.

Saslaw, S., and Campbeli, C. C. 1948 The use of yeast phase antigens in a complementfixation test for histoplasmosis. I. Preliminary results with rabbit sera. J. Lab. Clin. Med., 33, 811-818.

Smith, C. E., Saito, M. T., Beard, R. R., Kepp, R. M., Clark, R. W., ANd Eddie, B. E. 1950 Serological tests in the diagnosis and prognosis of coccidioidomycosis. Am. J. Hyg., 52, 1-21.

Tenenberg, D. J., and Howell, A. 1948 A complement fixation test for histoplasmosis. I. Technic and preliminary results on animal sera. Public Health Repts., 63, 163-168. 